\title{
Specific inhibitor of MEK-mediated cross-talk between ERK and p38 MAPK during differentiation of human osteosarcoma cells
}

\author{
Tsuyoshi Shimo • Shinsuke Matsumura • \\ Soichiro Ibaragi • Sachiko Isowa $\cdot$ Koji Kishimoto • \\ Hiroshi Mese • Akiyoshi Nishiyama • Akira Sasaki
}

Received: 10 May 2007 / Accepted: 7 August 2007 / Published online: 4 October 2007

(C) The International CCN Society 2007

\begin{abstract}
Osteosarcoma is the most common primary malignant bone tumor, accounting for approximately $20 \%$ of all primary sarcomas in bone. Although treatment modalities have been improved over the past decades, it is still a tumor with a high mortality rate in children and young adults. Based on histological considerations, osteosarcoma arises from impaired differentiation of these immature cells into more mature types and that correction of this impairment may reduce malignancy and increase the efficiency of chemotherapy. The purpose of this study was to determine the effect of specific inhibitors of MAPK extracellular signaling-regulated kinase (ERK) kinase (MEK) and p38 on the differentiation of human osteosarcoma cell line SaOS-2 cells. We found that PD98059, a specific inhibitor of MEK, inhibited the serum-stimulated proliferation of SaOS-2 cells; whereas SB203580, a specific inhibitor of p38 MAPK, had little effect on it. SB203580 suppressed ALPase activity, gene expression of type I collagen, and expression of ALP and BMP-2 mRNAs; whereas PD98059 upregulated them dose dependently. In addition, immunoblot and immunostaining analysis revealed that phosphorylation of ERK was increased by treatment with SB203580; whereas PD98059 increased the phosphorylation of $\mathrm{p} 38$, which implies a seesaw-like balance between ERK and p38 phosphorylation. We suggest that osteosarcoma cell differentiation is regulated by the balance between the activities of the ERK
\end{abstract}

T. Shimo $(\bowtie) \cdot \mathrm{S}$. Matsumura $\cdot \mathrm{S}$. Ibaragi $\cdot$ S. Isowa $\cdot$

K. Kishimoto $\cdot$ H. Mese $\cdot$ A. Nishiyama $\cdot$ A. Sasaki

Department of Oral and Maxillofacial Surgery and

Biopathological Science, Okayama University Graduate School

of Medicine, Dentistry, and Pharmaceutical Sciences,

2-5-1 Shikata-cho,

Okayama 700-8525, Japan

e-mail: shimotsu@md.okayama-u.ac.jp and p38 pathways and that the MEK/ERK pathway negatively regulates osteosarcoma cell differentiation, whereas the p38 pathway does so positively. MEK inhibitor may thus be a good candidate for altering the expression of the osteosarcoma malignant phenotype.

Keywords Mitogen-activated protein kinase .

Extracellular signal-regulated kinase $\cdot$ Differentiaton

\section{Background}

Osteosarcoma is the most frequent primary bone tumor (Goorin et al. 1985), and it has a marked tendency to recur and metastasize to the lungs and skeleton (Lane et al. 1986). It originates from undifferentiated mesenchymal cells and consists of osteoblastic, chondroblastic, and fibroblastic cells or their combination. These histologic features suggest that osteosarcoma arises from impaired differentiation of these immature cells into more mature types and that correction of this impairment may reduce malignancy and increase the efficiency of chemotherapy. Therefore, differentiation induction holds great potential as a new modality of cancer therapy (Hozumi 1983).

Mitogen-activated protein kinases (MAPKs) are prolinedirected serine-threonine kinases that have important functions as mediators of cellular responses to a variety of extracellular stimuli (Cano and Mahadevan 1995; Marshall 1995). Extracellular zsignal-regulated kinases (ERKs) are characteristically activated by various growth factors. Members of the p38 MAPK (p38) and c-Jun N-terminal kinase (JNK) subfamilies are strongly activated in response to stress stimuli (Raingeaud et al. 1995; Kyriakis et al. 1994) and thus proinflammatory cytokines, and have been given the name 
stress-activated protein kinases (SAPKs). Whereas the ERK pathway is usually associated with cell proliferation and protection from apoptosis, $\mathrm{p} 38$ and JNK ones can promote apoptosis in many systems (Xia et al. 1995). Recent studies suggest that, in addition to its effect on apoptosis, the p38 pathway might also be involved in the differentiation of neural cells (Iwasaki et al. 1999), adipocytes (Engelman et al. 1998), and chondrocytes (Yoshimichi et al. 2001; Shimo et al. 2005). In osteoblast-like cells, activation of ERK has been reported in response to several growth factors including mitogens acting through receptor tyrosine kinases (RTKs) such as basic fibroblast growth factor (bFGF; Suzuki et al. 2000), epidermal growth factor (EGF; Matsuda et al. 1998), platelet-derived growth factor (PDGF; Chaudhary and Avioli 1997), and insulin-like growth factor-1 (IFG-1; Kawane and Horiuchi 1999). As reported to be its effect in other cell systems, activation of ERK in osteoblast-like cells by growth factors is associated with enhanced cell proliferation. However, recent data have suggested that ERK might also be involved in the regulation of bone cell differentiation (Kawamura et al. 1999; Tokuda et al. 1999). Whereas studies using MC3T3-E1 cells suggest that activation of p38 is critical for ALP expression induced by fetal bovine serum (Suzuki et al. 2002). Differentiation of the bone marrow osteoprecursors was also inhibited in terms of ALP by a p38 inhibitor (Hu et al. 2003). In the present study, we investigated the effect of specific inhibitors of MEK and p38 on the differentiation of SaOS-2 cells and found that the MEK inhibitor enhanced and accelerated the differentiation but that the p38 inhibitor suppressed it. In addition we observed a seesaw-like phosphorylation between ERK and p38 when the cells were treated with the inhibitor for MEK or $\mathrm{p} 38$.

\section{Results}

Effect of ERK and p38 MAPK inhibitors

on the proliferation of SaOS-2 cells

Growth factors contained in FBS have been shown to play a critical role in the growth and differentiation of SaOS-2 cells (Bruserud et al. 2005). It is well documented that many growth factors can lead to the stimulation of different MAP kinases. To determine whether activation of ERK was required for serum-stimulated SaOS-2 cell proliferation, we incubated SaOS- 2 cells in fresh $\alpha \mathrm{MEM}+10 \%$ FBS in the presence of the ERK-specific MEK1/2 inhibitor PD98059 (20 $\mu \mathrm{M}$; Williamson et al. 2004). This inhibitor blocked the serum-stimulated proliferation of the cells; whereas incubation with the specific p38 inhibitor, SB203580 (Bebien et al. 2003), at $20 \mu \mathrm{M}$ had little effect on the up-regulation of proliferation by serum (Fig. 1a). a

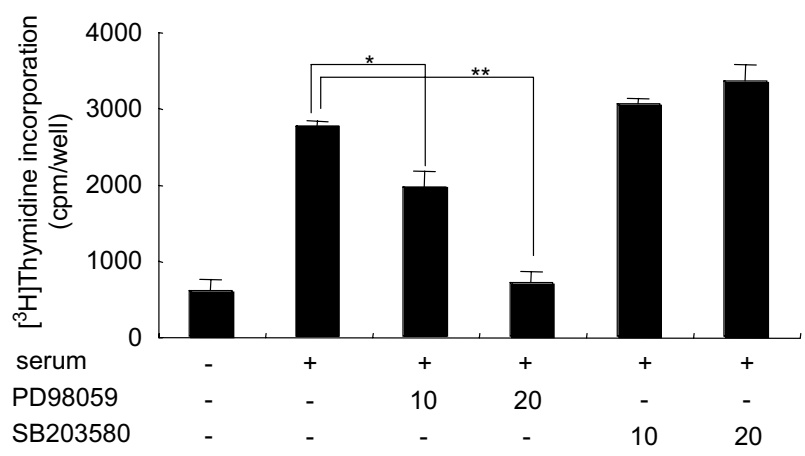

b

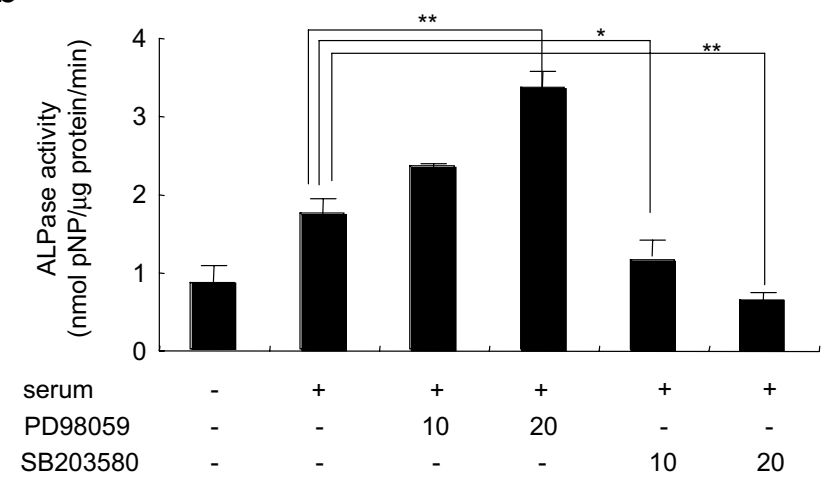

C

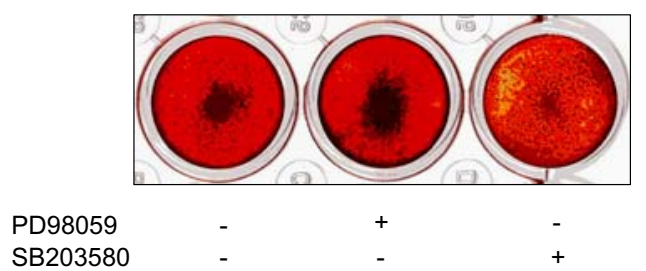

Fig. 1 Effects of MAPK inhibitors on SaOS-2 cell proliferation alkaline phosphatase activities and mineralization. a For the $\left[{ }^{3} \mathrm{H}\right]$ thymidine incorporation assay, cells were cultured with 10 or $20 \mu \mathrm{M}$ PD98059 or SB203580 for $18 \mathrm{~h}$, and the assay was performed as described under Materials and methods. b For the ALPase activity assay, cells were cultured with 10 or $20 \mu \mathrm{M}$ PD98059 or SB203580 for $48 \mathrm{~h}$, and the activity was determined as indicated in Materials and methods. c Photographs of bone nodules formation in 24-well multiplates. The data from a typical experiment are presented; similar results were obtained in 3 separate experiments. Asterisks indicate significant difference of $* p<0.05$ and ${ }^{* *} p<0.01$

Inhibition of ERK stimulated ALPase activity in SaOS-2 cells

To determine whether activation of ERK and p38 was required for SaOS-2 cell differentiation, we stimulated SaOS- 2 cells with fresh $\alpha \mathrm{MEM}+10 \%$ FBS in the presence of 10 or $20 \mu \mathrm{M}$ PD98059 or SB203580 for $48 \mathrm{~h}$. Treatment with SB203580 inhibited the ALPase activity dose dependently (Fig. 1b). In contrast, ALPase activity in the 
presence of PD98059 at $20 \mu \mathrm{M}$ was up-regulated (Fig. 1b), which concentration is sufficient to inhibit the ERKs in calvarial osteoblasts ( $\mathrm{Li}$ et al. 2002) and SaOS-2 cells (Juretic et al. 2001).

Effect of ERK and p38 MAPK inhibitors on the mineralization of SaOS-2 cells

To investigate whether activation of ERK and p38 was required for formation of mineralized bone nodules by SaOS-2 cells, these cells treated with $20 \mu \mathrm{M}$ PD98059 or SB203580 were cultured in the presence of $50 \mu \mathrm{g} / \mathrm{ml}$ ascorbic acid and $10 \mathrm{mM} \beta$-glycerophosphate $(\beta-\mathrm{GP})$ for 10 days. SaOS-2 cells treated with PD98059 showed marked mineralization, whereas SB203580 treated cells mineralization was inhibited compared to the control culture (Fig. 1c).

a

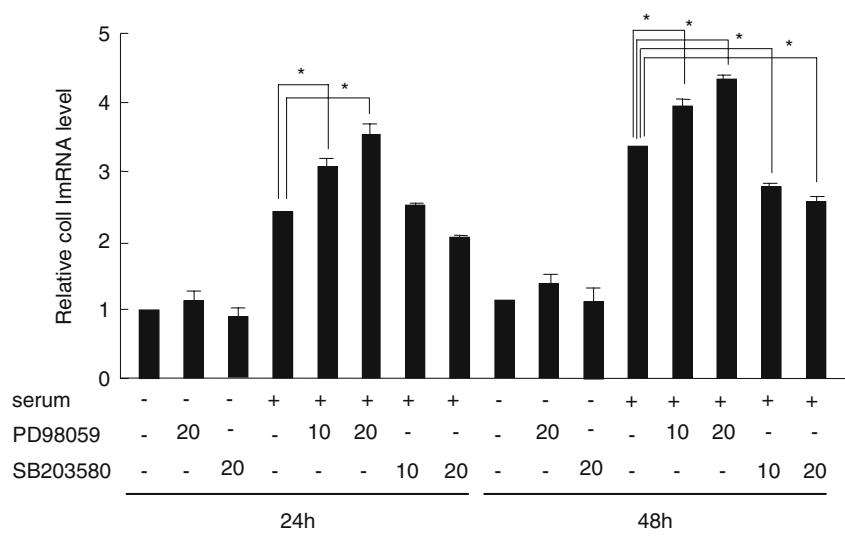

C

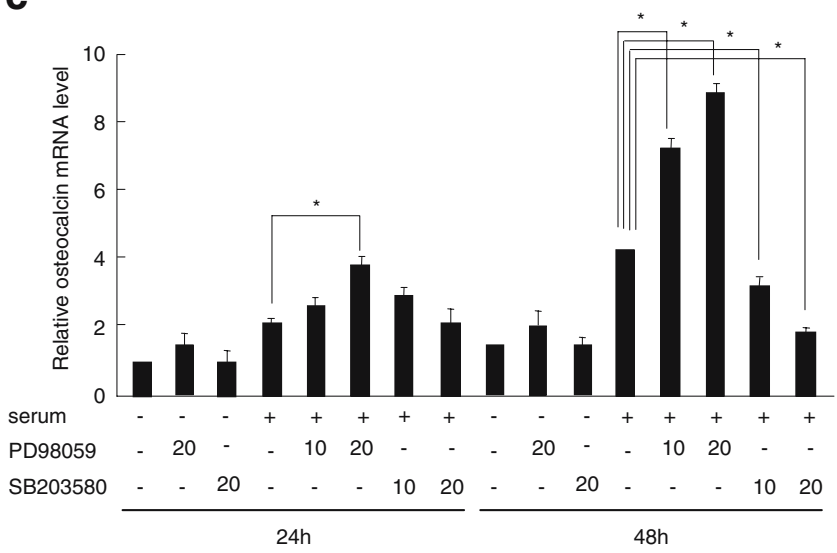

Fig. 2 Effect of MAPK inhibitors on the differentiation marker mRNAs in SaOS-2 cells. SaOS-2 cells were cultured for 7 days in complete $\alpha$ MEM containing $10 \%$ FBS. Then, the cells were changed with or without fresh $\alpha \mathrm{MEM}+10 \%$ FBS culture medium and then incubated for $12 \mathrm{~h}$. Thereafter the cells were treated with PD98059 or SB203580 for 24 or $48 \mathrm{~h}$; and their total RNA was analyzed by real-
MEK inhibitor enhanced and accelerated the differentiation in SaOS-2 cells

To determine whether activation of ERK and p38 was required for the early to late stage of SaOS-2 cell differentiation, we compared the mRNA expression of type I collagen, ALP, and osteocalcin in the presence of PD98059 or SB203580 with that in fresh 10\% FBS culture medium. PD98059 up-regulated type I collagen, ALP, and osteocalcin mRNA levels dose dependently; whereas increasing amounts of SB203580 suppressed those of type I collagen, ALP, and osteocalcin (Fig. 2a-c), indicating that activation of ERK inhibited early and late stages of SaOS-2 cell differentiation, whereas p38 stimulated them. However, type I collagen, ALP, and osteocalcin mRNA expression were not changed by PD98059 or SB203580 in the absence of serum (Fig. 3a-d). Bone morphogenetic proteins (BMPs)

b
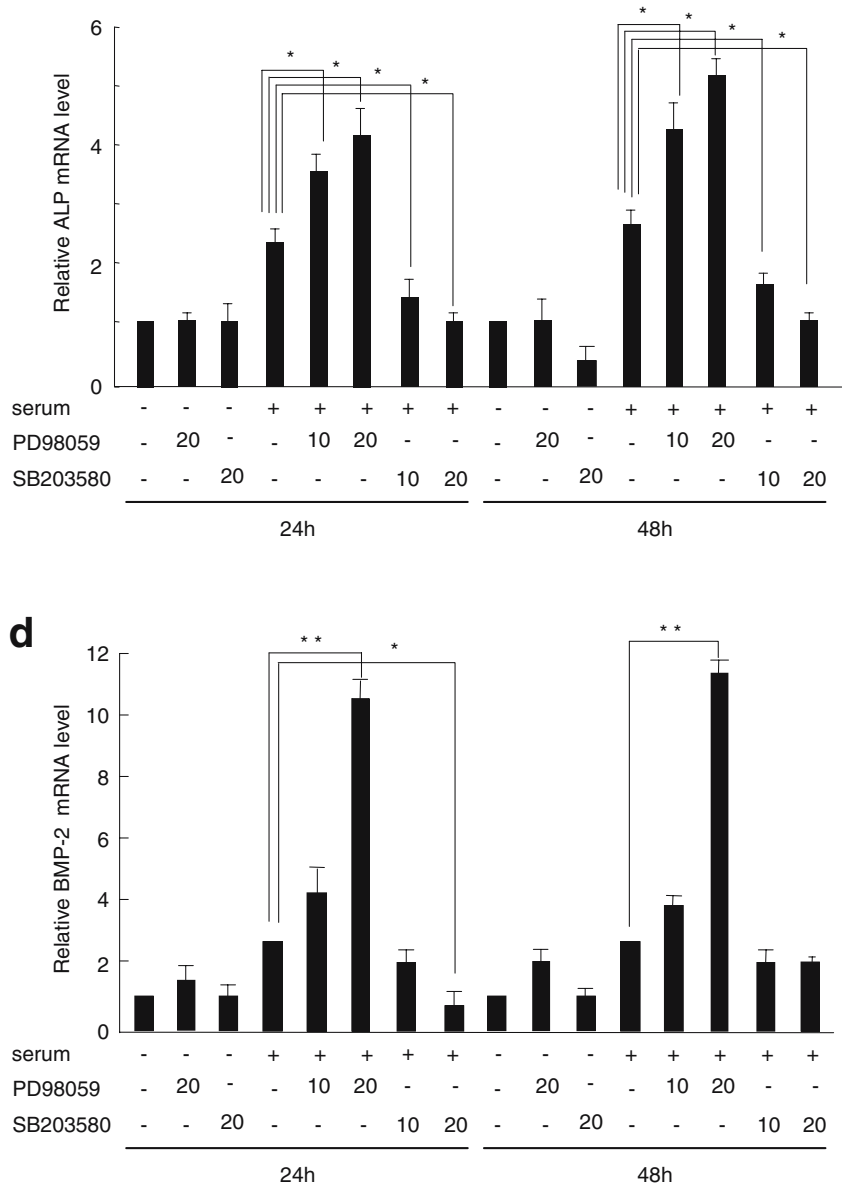

time RT-PCR for type I collagen (a), ALP (b), osteocalcin (c), and BMP-2 (d) mRNA. The data from a typical experiment are presented; similar results were obtained in 3 separate experiments. Asterisks indicate significance at $* p<0.05$ and $* * p<0.01$. The house-keeping gene GAPDH served as an internal control 
a

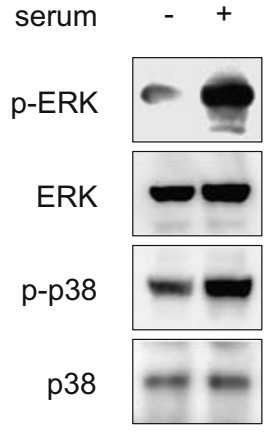

C

$\begin{array}{rcccccccccc}\text { PD98059 } & - & + & + & + & + & - & - & - & - & - \\ \text { SB203580 } & - & - & - & - & - & - & + & + & + & + \\ \min & 0 & 5 & 15 & 30 & 60 & 0 & 5 & 15 & 30 & 60\end{array}$

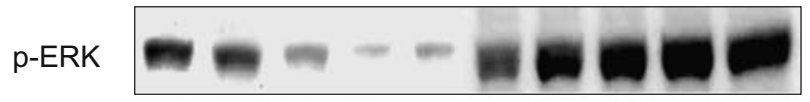

ERK

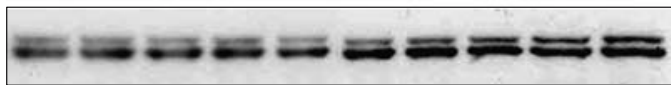

e

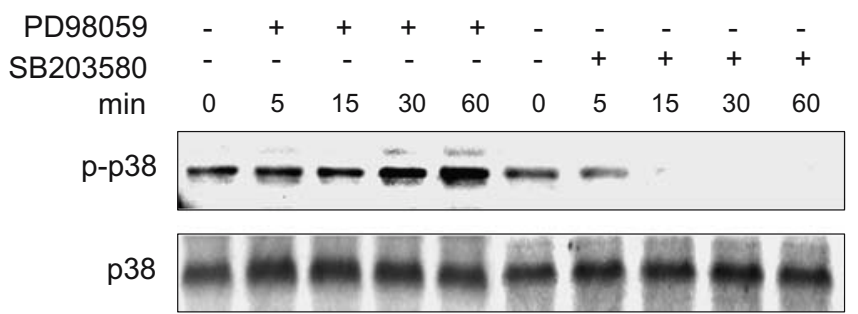

Fig. 3 Possible cross-talk between ERK and p38. a SaOS-2 cells were cultured for 7 days in complete $\alpha$ MEM containing $10 \%$ FBS. Then, the cells were either kept in the same medium or changed with fresh $\alpha \mathrm{MEM}+10 \% \mathrm{FBS}$; and $12 \mathrm{~h}$ later the cells were subjected to immunoblotting using anti-p-ERK or anti-p-p38. b-f SaOS-2 cells were cultured for 7 days in complete $\alpha$ MEM containing $10 \%$ FBS. Then, the cells were either kept in the same medium (b) or changed with fresh $\alpha \mathrm{MEM}+10 \%$ FBS culture medium $(\mathbf{c}-\mathbf{f})$; and $12 \mathrm{~h}$ later

are members of transforming growth factor- $\beta$ (TGF- $\beta$ ) family that play essential role in osteogenesis (Urist 1965). Treatment with $20 \mu \mathrm{M}$ PD98059 for 24 or $48 \mathrm{~h}$ upregulated BMP-2 mRNA expression, whereas that with SB203580 suppressed it (Fig. 2d).

\section{Cross-talk between ERK and p38}

New at al. (New et al. 2001) recently reported similar results; i.e., they observed the enhancement of ERK phosphorylation by treatment with SB203580 in PC12 cells in the presence of epidermal growth factor (EGF). Their finding prompted us to investigate the possibility of cross-talk between ERK and p38. Phosphorylation of ERK and $\mathrm{p} 38$ was increased $12 \mathrm{~h}$ after changing the culture medium to fresh $\alpha \mathrm{MEM}$ containing 10\% FBS (Fig. 3a). b

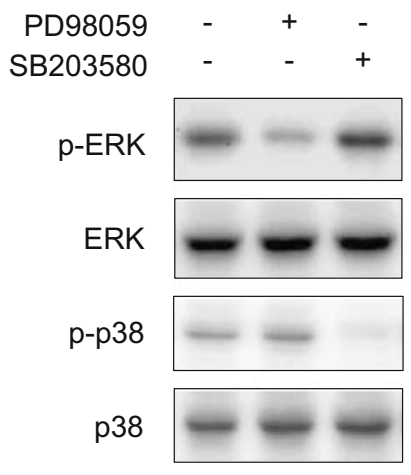

d

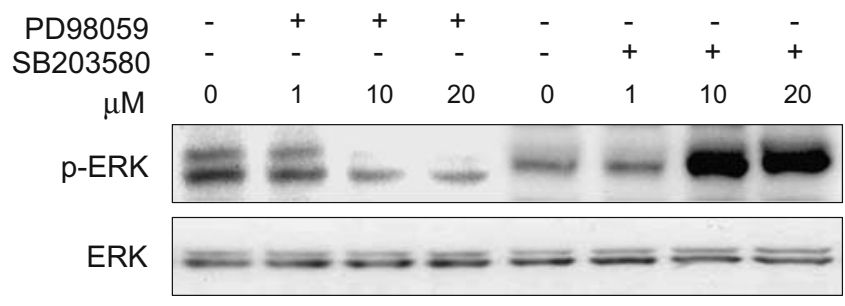

$\mathbf{f}$

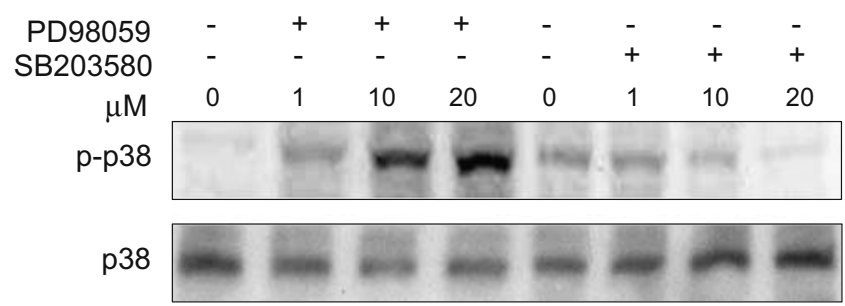

they were then treated with $20 \mu \mathrm{M}$ PD98059 or SB203580 for the indicated times (c and $\mathbf{e}$ ) or with various concentrations of PD98059 or SB203580 for $60 \mathrm{~min}$ (d and f). Cell lysate were processed for immunoblot determination of total ERK (c and d) and total p38 (e and f) or levels of phosphorylated ERK (c and d) and p38 (e and f), which are indicated as p-ERK and p-p38, respectively. The data from a typical experiment are presented; similar results were obtained in 3 separate experiments

SaOS- 2 cells were incubated with various concentrations of PD98059 or SB203580 in the presence of fresh $\alpha$ MEM containing $10 \%$ FBS and subjected to immunoblot analysis with anti-phospho-ERK and anti-phospho-p38. The phosphorylation of ERK was markedly decreased by PD 98059 but clearly increased in the presence of SB203580, both time and dose dependently (Fig. $3 b$ and c). On the other hand, phosphorylation of p38 was markedly suppressed by SB203580 but up-regulated in the presence of PD98059, in a time and dose-dependent manner (Fig. 3d and e). As shown in Fig. 4, the expression of phosphorylated ERK was markedly decreased by PD98059 (Fig. 4e) but markedly increased by SB203580 (Fig. 4f). On the other hand, the phosphorylation of p38 was suppressed by SB203580 (Fig. 4j) but up-regulated by PD98059 (Fig. 4i). However, PD98059 and SB203580 failed to 

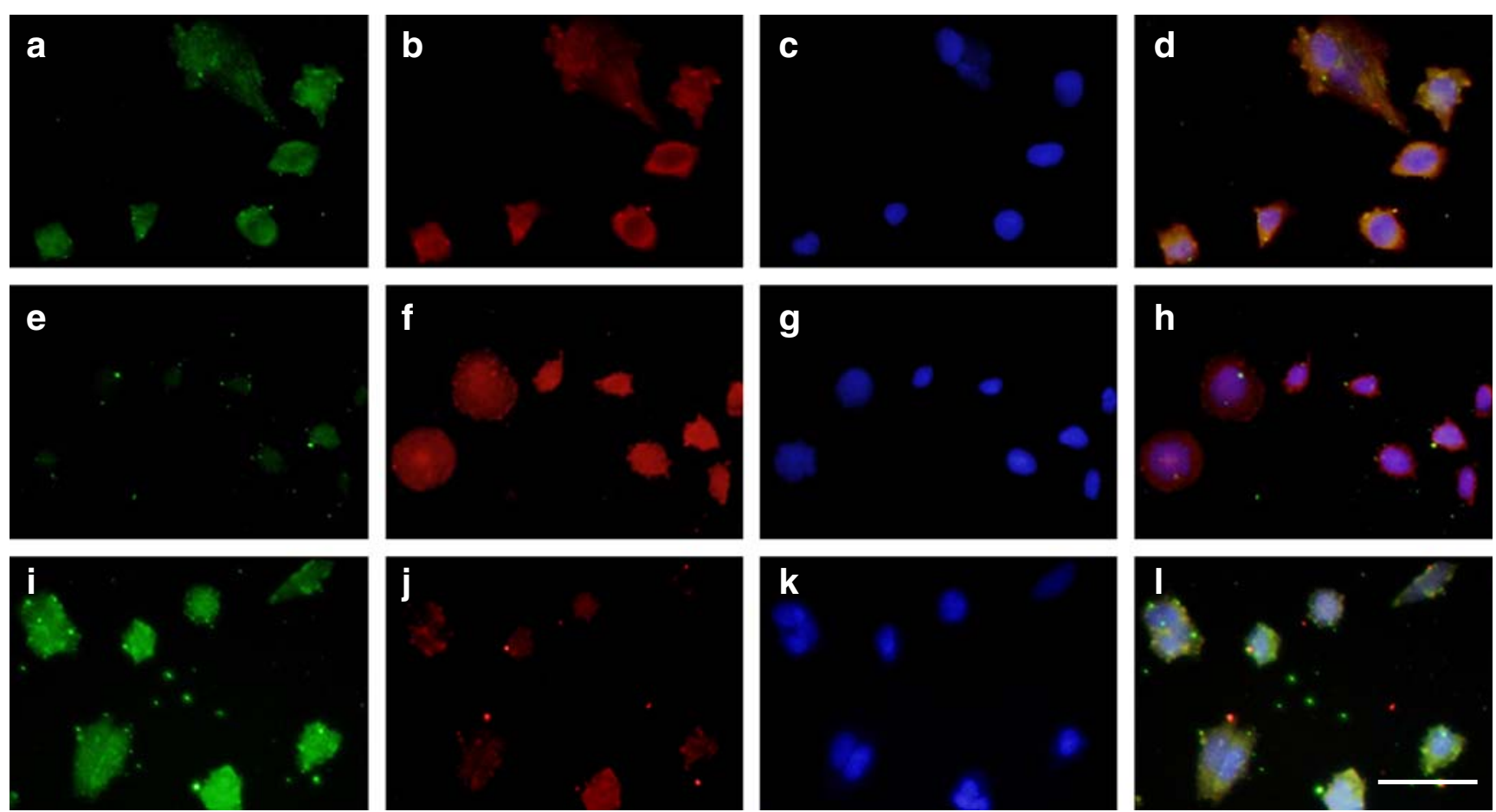

Fig. 4 Expression of phosphorylated forms of ERK and p38 in SaOS2 cells. (a-l) SaOS-2 cells were cultured for 4 days in complete $\alpha \mathrm{MEM}$ containing $10 \%$ FBS, and then the medium was changed to fresh $\alpha \mathrm{MEM}+10 \%$ FBS for $12 \mathrm{~h}$, after which the cells were treated with vehicle (a-d), $20 \mu \mathrm{M}$ PD98059 (e-h), or SB203580 (i-k) for

influence p38 and ERK closs-talk activation, respectively, in the absence of serum (Fig. 3b). Taken together, our data show that the p38 inhibitor increased the phosphorylation of ERK, and the MEK inhibitor increased that of p38 in compete culture medium containing 10\% FBS.

\section{Discussion}

In this report, the effects of MEK and p38 inhibitors on the differentiation of SaOS-2 cells were investigated. The MEK inhibitor markedly enhanced differentiation in the presence of serum, whereas the p38 inhibitor suppressed it. Activation of these signaling pathways in differentiating SaOS-2 cells after addition of fresh culture medium containing 10\% FBS is mediated by factors contained in the serum, because no stimulation of these MAPKs was detected when fresh culture medium containing no FBS was used (data not shown). The serum factors responsible for the stimulation of these MAPKs in osteosarcoma cells are not known, but are likely ligands for different types of receptors such as RTKs, G-protein-coupled receptors, and possibly cytokine receptors. Because chemical inhibitors of signal transduction are powerful tools to explore signaling pathways, their use has become more widespread to investigate what pathways are involved in cell responses such as growth and differentiation.

$60 \mathrm{~min}$. The cells were immunostained for phosphorylated ERK (a, e, and i) phosphorylated p38 (b, f, and j) and DAPI (c, g, and $\mathbf{k})$ and then photographed under a microscope. $\mathrm{d}, \mathrm{h}$, and $\mathrm{l}$ : merged image of phase-contrast microscopic views in "a-c", in "e-g" and in "i-k" respectively. Bar: $50 \mu \mathrm{m}$

Osteosarcoma cells at different osteoblastic stages display many of the features of differentiated osteoblasts, and the signal transduction pathway for osteosarcoma differentiation has been studied. Several research groups have investigated the involvement of MAPKs in this signaling pathway (Suzuki et al. 2002; Hu et al. 2003). As mentioned earlier, ERK is activated by growth factors acting through different types of receptors and mediates their mitogenic effects in bone-forming cells. As expected from this information, inhibiting the stimulation of ERK in response to FBS in proliferating SaOS-2 cells stopped their $\left[{ }^{3} \mathrm{H}\right]$ thymidine incorporation (Fig. 1a), thus confirming the importance of this pathway in regulating $\mathrm{SaOS}-2$ cell proliferation. We also demonstrated that ERKs played a negative role in serum-induced SaOS-2 cell differentiation. Blockage of MEK1/2 with the specific inhibitor PD98059 had a significant promotive effect on SaOS-2 cell differentiation. Our results are not in agreement with the findings that expression of dominant-negative ERK1 inhibited not only human osteoblast differentiation, but also proliferation, cell spreading, and migration (Lai et al. 2001). One explanation for the discrepancy is the cell source. Osteoblasts isolated from human bone chips were used in the experiments just cited, whereas we used a human osteosarcoma cell line. Another possibility is the difference between the inhibitor and the dominant-negative form of ERK1. 
Dominant-negative ERK1 suppressed the cellular differentiation, whereas PD98059 accelerated it. It is likely that PD98059 positively affected the p38 signaling pathwayinduced differentiation. Possible "seesaw-talk" between ERK and p38 signals may be proposed, which is discussed later on herein.

On the other hand, inhibition of $\mathrm{p} 38$ by its specific inhibitor, SB203580, interfered with the differentiation process of SaOS-2 cells. All of the differentiation markers, including type 1 collagen, ALP, and osteocalcin mRNAs, were reduced in the presence of the p38 inhibitor. These data suggest that activation of $\mathrm{p} 38$ is necessary for SaOS-2 cell differentiation. This suggestion is further supported by the fact that p38 MAPK is activated at the early stage of osteoblast differentiation (Suzuki et al. 2002). Furthermore, inhibition of p38 activity was associated with a slight increase in SaOS-2 cell proliferation, indicating that the $\mathrm{p} 38$ pathway is probably not involved in mediating the growth arrest that precedes the onset of SaOS-2 cell differentiation. However, inhibition of JNK by SP600125 was not associated with ALP and osteocalcin mRNAs when fresh culture medium containing 10\% FBS was used (data not shown). Indeed, SP600125 could not mediate the ALP and osteocalcin production in normal culture condition, but associated with small effects on ALP, and a marked and consistent decrease in osteocalcin production in response to BMP-2 in both MC3T3-E1 and calvaria cells (Guicheux et al. 2003). Taken together, these observations indicate that the JNK is implicated in BMP-2-induced osteoblastic cell differentiation with distinct regulatory effects on ALP and OC expression.

SaOS-2 cell differentiation is stimulated by local factors such as BMPs (Huang et al. 2002). Inhibition of p38 caused a delay in SaOS-2 cell differentiation. This delay may be partially released by the presence of BMP-2, suggesting that BMP-2 is able to overcome the loss of signals from p38 during SaOS-2 cell differentiation. Activation of p38 by BMP-2 is involved in ALP and osteocalcin expression (Guicheux et al. 2003). BMPs control osteoblast differentiation through Smad proteins that are inhibited by Tob (Yoshida et al. 2000). Activation of the BMP-Smad pathway may somehow compensate for the loss of p38. Further experiments will be needed to investigate the mechanism.

Immunoblot analysis using antibodies against phosphorylated MAP kinases revealed a "seesaw-talk" between ERK and p38: i.e., the MEK inhibitor caused a decrease in the level of phosphorylated ERK with an increase in that of phosphorylated p38, whereas the p38 inhibitor had the opposite effects. A similar seesaw cross-talk was previously reported, in which SB203580 by itself did not affect the activity of ERK but significantly extended EGF-induced ERK activation in PC12 cells (New et al. 2001). In
RAW264.7 cells, seesaw-like phosphorylation between ERK and p38 was observed when the cells were treated with inhibitors for MEK and p38 in the presence of RANKL (Bruserud et al. 2005). It is unlikely that secondary products derived from transcripts by transcription factors downstream of a MAPK pathway affected the other MAPK pathway, because the enhancement of phosphorylation by MAPK inhibitors took place after only 30 min. Previous studies have shown that SB203580 inhibits Raf production but paradoxically stimulates Raf activity (Hall-Jackson et al. 1999). This phenomenon could be due to a negative-feedback mechanism by which Raf inhibits itself. It is also known that SB239069, another highly selective p38 inhibitor, which does not inhibit Raf (Underwood et al. 2000), also increased $\mathrm{H}_{2} \mathrm{O}_{2}$-stimulated ERK phosphorylation (Liu and Hofmann 2004). Thus it is thus unlikely that the effect of SB203580 on ERK phosphorylation was due to its effect on Raf. A recent study demonstrated that activation of p38 can block the ERK pathway at the level of MEK through activation of protein phosphatase 2A (pp2A; Westermarck et al. 2001). Furthermore, SB203580 enhanced $\mathrm{H}_{2} \mathrm{O}_{2}$-stimulated ERK phosphorylation via pp2A in cardiac ventricular myocytes (Liu and Hofmann 2004). On the other hand, MAPK phosphatase (MKP)-1 is known to be up-regulated by ERK and to preferentially inactivate p38. PD98059 enhanced lipopolysaccharide-stimulated, p38 phosphorylation via MKP-1 in Raw 264.7 cells (Hotokezaka et al. 2002). Such findings may not be directly linked to the results in this study, but suggest the possibility that the chemical inhibitors may affect more than one molecule.

In conclusion, MEK inhibitor PD98059 suppressed serum-induced proliferation and up-regulated the differentiation of osteosarcoma cells. Further studies are needed to clarify the reciprocal effects of MAPK inhibitors on differentiation in SaOS-2 cells (Fig. 5) and to elucidate the seesaw cross-talk mechanism by which the inhibition of ERK or p38 phosphorylation by MEK or p38 inhibitors conversely induces p38 and ERK phosphorylation.

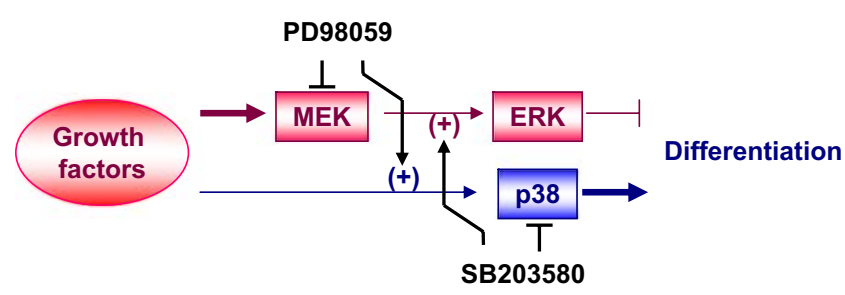

Fig. 5 Scheme showing the seesaw cross-talk, between MEK/ERK and p38 pathways during the differentiation of Saos- 2 cells. Growth factors contained in FBS activate both ERK and p38 pathways. The MEK/ERK pathway suppresses differentiation and is inhibited by PD98059. In contrast, the p38 pathway enhances differentiation and is inhibited by SB203580. PD98059 inhibits ERK and activates p38, whereas SB203580 inhibits p38 and activates ERK 


\section{Materials and methods}

\section{Materials}

The alpha modification of Eagle's medium ( $\alpha \mathrm{MEM})$ was purchased from Invitrogen Corporation (Grand Island, NY); and fetal bovine serum (FBS), from JRH Bioscience (Lenexa, KS). Plastic dishes and plates were from Becton Dickinson (Frabkin Lakes, NJ). $P$-nitrophenyl phosphate ( $p$-NPP) and $p$-nitrophenol ( $p$-NP) were purchased from Wako Pharmaceuticals (Osaka, Japan). [ $\left.{ }^{3} \mathrm{H}\right]$ Thymidine was obtained from Amersham Pharmacia Biotech (Aylesbury, UK). PD98059 and SB203580 came from Calbiochem (La Jolla, Ca). Anti-ERK1/2, p-ERK1/2, p38 and p-p38 antibodies were purchased from Santa Cruz Biotechnology (Santa Cruz, CA).

Cell culture

Human osteosarcoma cell line SaOS-2 cells were inoculated at a density of $1 \times 10^{6}$ cells/60-mm-diameter dish, $2 \times 10^{5}$ cells/ well in 12 -well multiplates, and $2 \times 10^{4}$ cells/ well in 96-well multiplates. These cells were cultured in $\alpha \mathrm{MEM}$ containing $10 \% \mathrm{FBS}$. All cells were cultured in $5 \% \mathrm{CO}_{2}$ in an atmosphere of $37^{\circ} \mathrm{C}$.

\section{$\left[{ }^{3} \mathrm{H}\right]$ thymidine incorporation assay}

The proliferation of SaOS-2 was assessed by measuring the incorporation of $\left[{ }^{3} \mathrm{H}\right]$ thymidine into the cells. SaOS-2 cells $\left(1 \times 10^{4}\right)$ were cultured in 96 -well plates under the conditions described in the figure legends and were pulsed with $\left[{ }^{3} \mathrm{H}\right]$ thymidine $(1 \mu \mathrm{Ci} / \mathrm{ml}$ of medium) for $4 \mathrm{~h}$ during incubation with test agents. The radioactivity incorporated into acidprecipitated material was counted by use of a microbeta scintillation counter (Micro Beta-PLUS; WALLAC).

\section{Alkaline phosphatase activity}

For estimation of ALPase activity, SaOS-2 cells was grown to confluence in 24-well multiplates with $\alpha \mathrm{MEM}$ containing $10 \%$ FBS. Then the cells were either kept in the same medium or the medium was exchanged for fresh $\alpha \mathrm{MEM}+$ $10 \%$ FBS containing 10 or $20 \mu \mathrm{M}$ PD98059 or SB203580 and incubated for $48 \mathrm{~h}$. After the incubation, the cells were rinsed with ice-cold phosphate-buffered saline (PBS), homogenized in $0.5 \mathrm{M}$ Tris ( $\mathrm{pH} 9.0$ ) containing $0.9 \% \mathrm{NaCl}$ and $1 \%$ Triton X-100 on ice, and centrifuged at $12,000 \mathrm{~g}$ for $15 \mathrm{~min}$. ALPase activity in the resultant supernatants was determined by the method of Bessey (Bessey et al. 1946) with some modifications. The enzyme reaction was initiated with $0.5 \mathrm{mM} p$-NPP in $0.5 \mathrm{M}$ Tris- $\mathrm{HCl}(\mathrm{pH} 9.0)$ containing $0.5 \mathrm{mM} \mathrm{MgCl} 2$ at $37^{\circ} \mathrm{C}$ and terminated by the addition of a quarter volume of $1 \mathrm{M} \mathrm{NaOH}$. The concentration of $p$-NP generated was determined by spectrophotometry at $410 \mathrm{~nm}$, and the enzyme activity was expressed as nmol $p$-NPP cleaved per minute per well.

\section{Mineralization assay}

Cells were inoculated at a density of $1 \times 10^{5}$ cells/well in 24-well multiplates and were cultured until confluent with MEM containing 10\% FBS. SaOS-2 cells were cultured in complete $\alpha$ MEM containing 10\% FBS, $50 \mu \mathrm{g} / \mathrm{ml}$ ascorbic acid and $10 \mathrm{mM} \beta$-GP in the presence of $20 \mu \mathrm{M}$ PD98059 or SB203580 for 10 days. The cells were fixed in $95 \%$ ethanol for $15 \mathrm{~min}$ at $37^{\circ} \mathrm{C}$, washed with $\mathrm{PBS}$, and stained with $1 \%$ alizarin red for $5 \mathrm{~min}$ at room temperature. DMSO was added to control cultures.

Immunoblot analysis

SaOS-2 monolayer cultures were rinsed with ice-cold PBS and lysed in ice-cold lysis buffer (50 mM Tris-HCl, $\mathrm{pH} 7.4$, containing $150 \mathrm{mM} \mathrm{NaCl}, 1 \%$ Triton X-100, 1\% NP-40, $10 \mathrm{mM} \mathrm{NaF}, 100 \mu \mathrm{M}$ leupeptin, $2 \mu \mathrm{g} / \mathrm{ml}$ aprotinin, and $1 \mathrm{mM}$ phenylmethyl sulfonyl fluoride) on ice. Cell lysates containing $10 \mu \mathrm{g}$ of total protein in lysis buffer were electrophoresed in 12\% SDS-PAGE gels (READYGELS, BIO-RAD) and the proteins were transferred to nylon membranes. The membranes were blocked with $2 \%$ nonfat dry milk in TBS overnight at $4{ }^{\circ} \mathrm{C}$ and then incubated with a 1:200 dilution of anti-p-ERK1/2, ERK1/2, p-p38 or p38 antibodies. Horseradish peroxidase-conjugated goat antirabbit or goat anti-mouse $\operatorname{IgG}$ were used as the secondary antibodies at a 1:1,000 dilution. Bands were visualized by using the ECL chemiluminescence detection method (RPN2109, Amersham Biosciences, UK).

\section{Quantitative real-time RT-PCR}

Total RNA was isolated using TRIzol reagent (Life Technologies Inc.), according to the manufacturer's instructions. Complementary DNA was generated from $1 \mu \mathrm{g}$ of total RNA using the First Strand cDNA Synthesis Kit (Invitrogen) in a final volume of $20 \mu \mathrm{l}$. Real-time RT-PCR was performed with a Light Cycler (Roche Molecular Biochemicals, Mannheim, Germany) in Light Cycler capillaries using a commercially available master mix containing Taq DNA polymerase and SYBR-Green I deoxyribonucleoside triphosphates (Light Cycler DNA master SYBR-Green I, Roche Molecular Biochemicals). After the addition of primers, $\mathrm{MgCl}_{2}(3 \mathrm{mM})$, and template DNA to the master mix, 65 cycles of denaturation $\left(95^{\circ} \mathrm{C}\right.$ for $\left.10 \mathrm{~s}\right)$, annealing, $\left(55^{\circ} \mathrm{C}\right.$ for $5 \mathrm{~s}$ ) and extension $\left(72^{\circ} \mathrm{C}\right.$ for $\left.10 \mathrm{~s}\right)$ were performed. Primers used were the following: 5'-CAGACTGGCAACCTCAA 
GAA-3' and 5'-GGAGGTCTTGGTGGTTTTGT-3' for type I collagen; 5'-CCCCGTGGCAACTCTATCTT-3' and 5'CTGCGCCTGGTAGTTGTTGT-3' for ALP; 5'-GAGGG CAGCGAGGTAGTGAA-3' and 5'-TCCTGAAAGCC GATGTGGTC-3' for osteocalcin; 5'-ATGCTAGACCTG TATCGC and 5'-TCGTTTCTGGTAGTTCTTCC-3'for BMP-2; and 5'-TGAACGGGAAGCTCACTGG-3' and 5'TCCACCACCCTGTTGCTGTA-3' for GAPDH. After the completion of PCR amplification, a melting curve analysis was performed. The fluorescence intensity of the doublestrand-specific SYBR Green I, reflecting the amount of formed PCR product, was monitored at the end of each elongation step. GAPDH mRNA levels were used to normalize the cDNA content of the samples.

\section{Immunofluorescence analysis}

After growth on culture slides, SaOS-2 cells were washed with PBS and fixed $20 \mathrm{~min}$ with cold methanol, and then permeabilized in $0.1 \% \mathrm{NP}-40$ in PBS. After the fixed cells had been washed three times with PBS, they were incubated at $4{ }^{\circ} \mathrm{C}$ overnight with the desired primary antibody in 3\% BSA-PBS. Then, the sections were washed three times with PBS and thereafter reacted with fluorescein isothiocyantate (FITC) or rodamine-conjugated anti-rabbit or anti-mouse $\mathrm{IgG}$ serum in $3 \%$ bovine serum albumin (BSA)-PBS for $1 \mathrm{~h}$. The sections were finally washed three times with PBS, and were mounted and viewed under a fluorescence microscope (IX81, Olympus, Tokyo, Japan).

\section{Statistical analysis}

Data were analyzed by using the Fisher's protected least significant difference (Fisher's PLSD) for analysis of multiple group comparisons. Results were expressed as the mean \pm S.D. $\mathrm{p}<0.05$ was considered statistically significant.

Acknowledgements This work was supported in part by grants from the Uehara Memorial Foundation (T. S.), the Okayama Health Foundation (T. S.), the Ryobi-teien Memorial Foundation (T. S.), the Okayama Medical Foundation (T. S.), the programs Grants-in-Aid for Young Scientists [A and B] (T. S.), Scientific Research [B] (A. S.) of the Ministry of Education, Culture, Sports, Science, and Technology.

Competing interests The authors declare that they have no competing interests.

\section{References}

Bebien M, Salinas S, Becamel C, Richard V, Linares L, Hipskind RA (2003) Immediate-early gene induction by the stresses anisomycin and arsenite in human osteosarcoma cells involves MAPK cascade signaling to Elk-1, CREB and SRF. Oncogene 22 (12):1836-1847

Bessey OA, Lowry OH, Brock MJ (1946) A method for the rapid determination of alkaline phosphatase with five cubic millimerters of serum. J Biol Chem 164:321-329

Bruserud O, Tronstad KJ, Berge R (2005) In vitro culture of human osteosarcoma cell lines: a comparison of functional characteristics for cell lines cultured in medium without and with fetal calf serum. J Cancer Res Clin Oncol 131(6):377-384

Cano E, Mahadevan LC (1995) Parallel signal processing among mammalian MAPKs. Trends Biochem Sci 20(3):117-122

Chaudhary LR, Avioli LV (1997) Activation of extracellular signalregulated kinases 1 and 2 (ERK1 and ERK2) by FGF-2 and PDGF-BB in normal human osteoblastic and bone marrow stromal cells: differences in mobility and in-gel renaturation of ERK1 in human, rat, and mouse osteoblastic cells. Biochem Biophys Res Commun 238(1):134-139

Engelman JA, Lisanti MP, Scherer PE (1998) Specific inhibitors of p38 mitogen-activated protein kinase block 3T3-L1 adipogenesis. J Biol Chem 273(48):32111-32120

Goorin AM, Abelson HT, Frei E (1985) Osteosarcoma: fifteen years later. N Engl J Med 313(26):1637-1643

Guicheux J, Lemonnier J, Ghayor C, Suzuki A, Palmer G, Caverzasio J (2003) Activation of p38 mitogen-activated protein kinase and c-Jun-NH2-terminal kinase by BMP-2 and their implication in the stimulation of osteoblastic cell differentiation. J Bone Miner Res 18(11):2060-2068

Hall-Jackson CA, Goedert M, Hedge P, Cohen P (1999) Effect of SB 203580 on the activity of c-Raf in vitro and in vivo. Oncogene 18 (12):2047-2054

Hotokezaka H, Sakai E, Kanaoka K, Saito K, Matsuo K, Kitaura H, Yoshida N, Nakayama K (2002) U0126 and PD98059, Specific inhibitors of MEK, accelerate differentiation of RAW264.7 cells into osteoclast-like cells. J Biol Chem 277(49):47366-47372

Hozumi M (1983) Fundamentals of chemotherapy of myeloid leukemia by induction of leukemia cell differentiation. Adv Cancer Res 38:121-169

$\mathrm{Hu}$ Y, Chan E, Wang SX, Li B (2003) Activation of p38 mitogenactivated protein kinase is required for osteoblast differentiation. Endocrinology 144(5):2068-2074

Huang W, Rudkin GH, Carlsen B, Ishida K, Ghasri P, Anvar B, Yamaguchi DT, Miller TA (2002) Overexpression of BMP-2 modulates morphology, growth, and gene expression in osteoblastic cells. Exp Cell Res 274(2):226-234

Iwasaki S, Iguchi M, Watanabe K, Hoshino R, Tsujimoto M, Kohno M (1999) Specific activation of the p38 mitogen-activated protein kinase signaling pathway and induction of neurite outgrowth in PC12 cells by bone morphogenetic protein-2. J Biol Chem 274 (37):26503-26510

Juretic N, Santibanez JF, Hurtado C, Martinez J (2001) ERK 1,2 and p38 pathways are involved in the proliferative stimuli mediated by urokinase in osteoblastic SaOS-2 cell line. J Cell Biochem 83 (1):92-98

Kawamura H, Otsuka T, Tokuda H, Matsuno H, Niwa M, Matsui N, Uematsu T, Kozawa O (1999) Involvement of p42/p44 MAP kinase in endothelin-1-induced interleukin- 6 synthesis in osteoblastlike cells. Bone 24(4):315-320

Kawane T, Horiuchi N (1999) Insulin-like growth factor I suppresses parathyroid hormone $(\mathrm{PTH}) / \mathrm{PTH}$-related protein receptor expression via a mitogen-activated protein kinase pathway in UMR-106 osteoblast-like cells. Endocrinology 140(2):871-879

Kyriakis JM, Banerjee P, Nikolakaki E, Dai T, Rubie EA, Ahmad MF, Avruch J, Woodgett JR (1994) The stress-activated protein kinase subfamily of c-Jun kinases. Nature 369(6476):156-160

Lai CF, Chaudhary L, Fausto A, Halstead LR, Ory DS, Avioli LV, Cheng SL (2001) ERK is essential for growth, differentiation, 
integrin expression, and cell function in human osteoblastic cells. J Biol Chem 276(17):14443-14450

Lane JM, Hurson B, Boland PJ, Glasser DB (1986) Osteogenic sarcoma. Clin Orthop Relat Res 204:93-110

Li B, Ishii T, Tan CP, Soh JW, Goff SP (2002) Pathways of induction of peroxiredoxin I expression in osteoblasts: roles of p38 mitogen-activated protein kinase and protein kinase C. J Biol Chem 277(14):12418-12422

Liu Q, Hofmann PA (2004) Protein phosphatase 2A-mediated crosstalk between p38 MAPK and ERK in apoptosis of cardiac myocytes. Am J Physiol Heart Circ Physiol 286(6):2204-2212

Marshall CJ (1995) Specificity of receptor tyrosine kinase signaling: transient versus sustained extracellular signal-regulated kinase activation. Cell 80(2):179-185

Matsuda N, Morita N, Matsuda K, Watanabe M (1998) Proliferation and differentiation of human osteoblastic cells associated with differential activation of MAP kinases in response to epidermal growth factor, hypoxia, and mechanical stress in vitro. Biochem Biophys Res Commun 249(2):350-354

New L, Li Y, Ge B, Zhong H, Mansbridge J, Liu K, Han J (2001) SB203580 promotes EGF-stimulated early morphological differentiation in PC12 cell through activating ERK pathway. J Cell Biochem 83(4):585-596

Raingeaud J, Gupta S, Rogers JS, Dickens M, Han J, Ulevitch RJ, Davis RJ (1995) Pro-inflammatory cytokines and environmental stress cause p38 mitogen-activated protein kinase activation by dual phosphorylation on tyrosine and threonine. J Biol Chem 270 (13):7420-7426

Shimo T, Koyama E, Sugito H, Wu C, Shimo S, Pacifici M (2005) Retinoid signaling regulates CTGF expression in hypertrophic chondrocytes with differential involvement of MAP kinases. J Bone Miner Res 20(5):867-877

Suzuki A, Palmer G, Bonjour JP, Caverzasio J (2000) Stimulation of sodium-dependent phosphate transport and signaling mechanisms induced by basic fibroblast growth factor in MC3T3-E1 osteoblast-like cells. J Bone Miner Res 15(1):95-102

Suzuki A, Guicheux J, Palmer G, Miura Y, Oiso Y, Bonjour JP, Caverzasio J (2002) Evidence for a role of p38 MAP kinase in expression of alkaline phosphatase during osteoblastic cell differentiation. Bone 30(1):91-98

Tokuda H, Kozawa O, Harada A, Uematsu T (1999) p42/p44 mitogenactivated protein kinase activation is involved in prostaglandin F2alpha-induced interleukin-6 synthesis in osteoblasts. Cell Signal 11(5):325-330

Underwood DC, Osborn RR, Kotzer CJ, Adams JL, Lee JC, Webb EF, Carpenter DC, Bochnowicz S, Thomas HC, Hay DW, Griswold DE (2000) SB 239063, a potent p38 MAP kinase inhibitor, reduces inflammatory cytokine production, airways eosinophil infiltration, and persistence. J Pharmacol Exp Ther 293(1): 281-288

Urist MR (1965) Bone: formation by autoinduction. Science 150 (698):893-899

Westermarck J, Li SP, Kallunki T, Han J, Kahari VM (2001) p38 mitogen-activated protein kinase-dependent activation of protein phosphatases 1 and 2A inhibits MEK1 and MEK2 activity and collagenase 1 (MMP-1) gene expression. Mol Cell Biol 21 (7):2373-2383

Williamson AJ, Dibling BC, Boyne JR, Selby P, Burchill SA (2004) Basic fibroblast growth factor-induced cell death is effected through sustained activation of p38MAPK and upregulation of the death receptor p75NTR. J Biol Chem 279 (46):47912-47928

Xia Z, Dickens M, Raingeaud J, Davis RJ, Greenberg ME (1995) Opposing effects of ERK and JNK-p38 MAP kinases on apoptosis. Science 270(5240):1326-1331

Yoshida Y, Tanaka S, Umemori H, Minowa O, Usui M, Ikematsu N, Hosoda E, Imamura T, Kuno J, Yamashita T, Miyazono K, Noda M, Noda T, Yamamoto T (2000) Negative regulation of $\mathrm{BMP} / \mathrm{Smad}$ signaling by Tob in osteoblasts. Cell 103(7): 1085-1097

Yoshimichi G, Nakanishi T, Nishida T, Hattori T, Takano-Yamamoto T, Takigawa M (2001) CTGF/Hcs24 induces chondrocyte differentiation through a p38 mitogen-activated protein kinase (p38MAPK), and proliferation through a p44/42 MAPK/extracellular-signal regulated kinase (ERK). Eur J Biochem 268 (23):6058-6065 